\title{
LA PRÁCTICA PROFESIONAL DEL ARQUITECTO EN LATINOAMÉRICA
}

Autores: Carlos E. Barducco, Sergio A. Solís, Laura V. Barducco

Asignaturas Organización de Obras y Taller de Práctica Profesional

Facultad de Arquitectura, Diseño y Urbanismo, Universidad Nacional del Litoral

Santa Fe, Argentina. Ciudad Universitaria Paraje El Pozo.

Email: carlosbarducco@yahoo.com.ar

Palabras clave: ejercicio profesional, vínculos regionales, enseñanza, actualización e integración de conocimientos.

\section{Resumen:}

Pensar en estrategias pedagógicas que preparen a los estudiantes de la carrera de Arquitectura y Urbanismo de la Facultad de Arquitectura, Diseño y Urbanismo de la Universidad Nacional del Litoral (FADU-UNL) para su futura inserción en un mercado de trabajo cada vez más globalizado, motiva la formulación constante de ámbitos de reflexión sobre los procesos de enseñanza.

La propuesta, enmarcada en el Programa de Internacionalización Integral de Espacios Curriculares de la UNL, persigue, entre otros, el objetivo de actualización permanente de los conocimientos, en la búsqueda de espacios que originen instancias de trabajo que estimulen la integración en el ámbito regional e internacional.

La práctica profesional del arquitecto, como conjunto de instrumentos y procedimientos disciplinares, se ubicará en el centro de esta proposición. Basada en el saber científico, teórico, universal, necesita sin embargo de otros saberes relacionados con el hacer particular, que le permita desempeños adecuados a diversos contextos y realidades.

En términos de herramientas cognitivas en este particular proceso de enseñanza, se pretende comprender el objeto de estudio, la práctica profesional del arquitecto, desde diversas realidades y contextos pero con la misma función social que le cabe a la disciplina.

Desde el diseño curricular el abordaje de la temática se plantea en el ámbito académico, aunque por su naturaleza se sabe que involucrará otras cátedras, áreas y ciclos dentro de las Facultades y Universidades, como así también a otras instituciones externas a la universidad, organizaciones profesionales, empresariales, estatales y/u otras; en tanto todas ellas se relacionen directamente con el ejercicio de las incumbencias del arquitecto.

\section{Introducción.}

El espacio curricular que se propone, caracterizado por contextos globales y particulares, al mismo tiempo según lo descrito, buscará una preparación de los estudiantes para el acceso al mundo del trabajo que los espera tras su titulación, con énfasis en aspectos propios del ejercicio profesional, configurando éste el eje principal de la presente iniciativa, la cual, entre otros, plantea los siguientes objetivos de trabajo:

- En este particular espacio de enseñanza el objeto de estudio será la práctica profesional del arquitecto, enmarcado en circunstancias de incumbencias, formación y abordado desde las diversas realidades y contextos que muestra la disciplina en este ámbito regional latinoamericano al que está dirigido.

- Los espacios académicos actuales donde se asienta y origina esta propuesta, que en el plan de estudio de la FADU-UNL se ubican en niveles correspondientes al ciclo Superior de la carrera y que hoy están dirigidos fundamentalmente al ámbito local, nacional, pretende extrapolar criterios y acciones a espacios análogos de otras casas de estudio, por entender que es donde se logra la integración y síntesis de conocimientos adquiridos durante los estudios y constituyen los espacios curriculares principales para la afirmación de las incumbencias y las prácticas profesio- 
nales.

- Los análisis comparativos entre asignaturas y/o planes de estudio de ésta con otras universidades internacionales, significará un punto de partida para definir tópicos y modalidades tendientes a plantear estrategias de enseñanza con ese alcance geo-institucional, en pos de poder brindar a los alumnos este tipo de competencias, cada vez más necesarias para el desempeño profesional en diferentes ámbitos de trabajo, hoy hermanados, globalizados.

- Los contenidos o temas que hagan al ámbito multicultural al que se apunta, en relación a las distintas realidades de la temática disciplinar, se podrán identificar del estudio comparado de incumbencias y currículos. Ello requerirá la implementación de actividades de intercambio de experiencias, promoviendo clases-talleres a distancia y/o presenciales, prácticas concretas, convenios de movilidad académica, de manera que se puedan plantear y resolver distintas problemáticas, desde diferentes contextos, pero todas congruentes con las expectativas específicas y humanas del conjunto de los estudiantes, docentes y destinatarios.

- La propuesta está dirigida a un universo latinoamericano donde el idioma español, como lengua común, facilitará el desarrollo de actividades conjuntas. No obstante se estima que deberán promoverse o fortalecerse otros idiomas como por ejemplo el portugués, propio de un país como Brasil que regional, académica y profesionalmente está muy vinculado con el nuestro. Además del idioma inglés, en tanto herramienta indispensable para poder acceder a los conocimientos y prácticas de otros niveles de sociedades y regiones internacionales; y que puedan significar aportes aplicables a nuestras realidades.

\section{La propuesta.}

\subsection{Tipo de espacio curricular y destinatarios.}

En esta propuesta, que como ya se ha mencionado está enmarcada el Programa de Internacionalización Integral de Espacios Curriculares de la UNL, participan las asignaturas detalladas a continuación, que pertenecen al ciclo superior y al área de las tecnologías de la carrera de Arquitectura y Urbanismo de la FADU-UNL; ambas de carácter obligatorio en el plan de estudio vigente.

- Organización de obras. Ciclo superior - 5to. Nivel - Carácter anual. Modalidad de dictado: presencial, teórico-práctica.

- Taller de práctica profesional. Ciclo superior- 6to. Nivel - Carácter cuatrimestral. Modalidad de dictado: presencial, teórico-práctica.

Dentro de los espacios curriculares arriba indicados, se piensa en una modalidad de dictado conformada inicialmente (primera fase de cumplimiento de metas) de un Módulo con las temáticas y actividades a internacionalizar, cuyas actividades tendrán diversas modalidades, como ser clase-taller; seminarios; jornadas de encuentro, otras. Posteriormente (segunda fase de metas y objetivos) se aspira a constituir una Materia Optativa, para así mejor disponer los recursos que se asignen; y de este modo ampliar el conjunto de actividades y otros aspectos de la oferta educativa.

Los destinatarios de la propuesta son, para el caso local, estudiantes de grado de la carrera de Arquitectura y Urbanismo, que cursan las asignaturas detalladas, y cuyas condiciones de cursado son las establecidas en el régimen de exigencias y correlatividades del plan de estudio vigente. También podrán ser estudiantes extranjeros, que cursen en la FADU-UNL, incorporados al cursado de las citadas asignaturas mediante convenios o programas específicos y según condiciones y exigencias que en los mismos se estipulen.

Podrán ser también, para el caso externo, aquellos estudiantes de grado de la carrera de Arquitectura, que desarrollen actividades contenidas en esta propuesta, en espacios curriculares de las universidades latinoamericanas que acuerden y participen de la presente iniciativa académica; debiendo reunir las condiciones y exigencias que en ella se determinen.

En cualquier caso, se pretende que esta experiencia académica, dada su naturaleza y objetivos, recaiga en las asignaturas del tramo final de la formación de grado del arquitecto, instancia de los planes de estudios en la que necesariamente se producen la integración y síntesis de conoci- 
mientos y que por otra parte se ubica próxima al punto final de la graduación.

\subsection{Metodología de trabajo}

Dada la naturaleza de la propuesta se establece una metodología de trabajo de avances progresivos, con distintas metas a alcanzar, conforme se vayan cumpliendo las acciones e hipótesis de trabajo, tendientes a lograr:

- Progresividad en la integración de actores. Según se plantea y de acuerdo a la diversidad de instituciones y personas que se vayan integrando, dependerá tener mayores posibilidades de aprendizajes y actividades. Se propone un inicio con dos instituciones latinoamericanas más la UNL, de modo de constituir el punto de partida de una red que se pretende tenga al final un alcance y representatividad continental.

- Progresividad en la realización de actividades académicas. También para las acciones sustantivas se propone ir desarrollando actividades y cumpliendo objetivos; que con el tiempo pueda significar las bases para establecer un calendario o cronograma de trabajo integrado. Se comenzarán con las actividades que establezcan las instituciones iniciadoras, previendo reconfiguraciones de programas y modalidades conforme lo requieran nuevas incorporaciones a esta red. Dichas metas parciales se tratarán de alcanzar organizando las actividades a partir del desarrollo en dos tramos con modalidades pedagógicas bien diferenciadas:

1. Cátedras espejo: en principio se propone se desarrollen en el seno de las cátedras análogas de cada facultad, que deberán destinar tiempo y espacio académico para una tarea coordinada, de modo de no generar en los comienzos requerimientos y/o recursos significativos en relación a los disponibles y/o puestos para el dictado de la Asignatura donde se ubica esta actividad.

La modalidad pedagógica que se propone y que en definitiva deberá acordarse y coordinar su realización, tendría las siguientes instancias académicas:

- Elección de un tema de los contenidos generales o programa, para abordar la tarea y planteamiento de las consignas para su realización.

- Desarrollo en paralelo de clases teóricas, clases especiales, charlas, seminarios, para el abordaje de los contenidos temáticos elegidos para esta actividad y elaboración de trabajo práctico según lo consignado, a modo de presentación o exposición.

- Socialización de los trabajos prácticos entre las cátedras participantes para la evaluación que se establezca realizar y que en cualquier caso hará énfasis en análisis comparativos de temáticas específicas y realidades contextuales.

Sin perjuicio de lo que establezcan las pautas de realización de cada trabajo, se propone como modalidad operativa general la realización de trabajo/s práctico/s en formato digital con una vinculación a distancia de los actores mediante comunicaciones vía mail u otras posibilidades que brinda la red global. Todas las actividades serán coordinadas y plasmadas en un cronograma a definir para las actividades anuales o semestrales en general, y para cada trabajo o abordaje en particular.

2. Encuentro de cátedras: se propone se desarrollen encuentros presenciales en las instituciones participantes, en modo rotativo y debidamente organizadas, de forma tal de reforzar la vinculación de experiencias a través de la interacción directa de sus actores.

Estos encuentros que tendrán algún formato usual (seminario, jornadas, workshop) deberán programarse y organizarse teniendo en cuenta los recursos que se requieren para su realización, en lo atinente a organización, traslados y alojamientos, para lo cual oportunamente con cada Institución, Cátedra o Docente, y con un espíritu de esfuerzo compartido, deberá acordarse el mejor modo de solventar de esta actividad.

En este caso, la modalidad pedagógica que se propone, tendría las siguientes instancias académicas:

- Elección de un tema de los contenidos generales o programa, a modo de disparador o 
título convocante del evento y planteamiento de modalidades o formatos de realización.

- Desarrollo de jornadas con exposiciones, debates y análisis comparativos de los trabajos producidos en las cátedras espejo, a modo de síntesis y reflexiones acerca de las temáticas específicas abordadas según las diferentes realidades contextuales

- Dictado de charlas, conferencias, clases magistrales, clases en cursos de grado como invitado, a cargo de los Docentes visitantes, en relación a los contenidos temáticos elegidos para el evento u otros, de modo de posibilitar un acercamiento de docentes, alumnos, instituciones, con el objetivo de conocer más profundamente aspectos del ejercicio profesional del arquitecto en la región latinoamericana.

- Asimismo, sin perjuicio de lo que establezcan las pautas de convocatoria del evento, se propone como modalidad operativa general la elección de la sede, anual, rotativa, quien se hará cargo de la organización del mismo; mientras que los aspectos relacionados con traslados y alojamientos se coordinarán en cada caso. Como las demás actividades de este espacio curricular internacional serán coordinadas y plasmadas en un cronograma a definir, en este caso para las actividades anuales.

En términos generales, considerando ambas modalidades, también resulta interesante formular las siguientes instancias:

- Divulgación: se propone como actividades finales de años o períodos, la divulgación de actividades y producidos, que permitan ampliar el conjunto de destinatarios y trascender el ámbito académico universitario. Eventualmente pensar en alguna publicación, en algunos de los formatos actuales.

- Materia optativa: si bien en sus inicios las estrategias y modalidades se plantean en el seno de las asignaturas Taller de Práctica Profesional y Organización de Obras, en un futuro se estima procedente proponer la estructuración de una materia optativa en la FADU-UNL. Ello permitirá plasmar en un espacio curricular propio, mejores modos organizativos, administrativos y de recursos, una oferta académica con esta temática de alcance regional-continental.

- Práctica de alumnos: se promoverá que las prácticas que alumnos de la FADU-UNL realizan en el exterior a través de los distintos programas disponibles; como así también las que los alumnos extranjeros desarrollan en la FADU-UNL, tengan en este espacio curricular específico, con temáticas y metodologías comunes, acordadas, un ámbito de contención y reflexión para que su experiencia avance en la dirección de conocimiento y desempeño en realidades y contextos diferentes, pero todos igualmente posibles, cercanos, a su futuro profesional.

Para la evaluación del trabajo que realicen los estudiantes de grado locales, se adoptará básicamente la indicada en las Planificaciones de las asignaturas, con las modificaciones que amerite la particularidad de este espacio curricular. Para el caso de estudiantes extranjeros, tendrán las análogas indicadas en sus respectivas asignaturas y universidad. Para el caso de encuentros de cátedras, y de acuerdo con las actividades que se organicen, se adoptarán sistemas compartidos con docentes extranjeros asistentes, pudiendo constituir comité de evaluación y/o jurados de talleres, encierros u otros desarrollos que se efectúen en las jornadas previstas.

\subsection{Contenidos.}

Se enuncian ejes o contenidos temáticos generales, tomados de las asignaturas involucradas en la propuesta, los que se considera que pueden estar presentes en una agenda común de todos los integrantes y destinatarios. Por ello no tienen un carácter taxativo y se espera sirvan a los fines de que mediante consultas y acuerdos pertinentes, puedan constituir un programa para este espacio curricular nuevo. Con ese objeto se propone:

- Formación e Incumbencias.

- $\quad$ Ejercicio profesional. Roles: Proyectista, Director, otros. Ámbitos: público, privado. Regulaciones: Entes, Asociaciones y otras.

- Documentación: de proyecto, de obras y otras instancias. 
- Tramitaciones, gestiones, procedimientos técnicos-administrativos.

- Tecnologías.

- Sustentabilidad.

- Usos y costumbres; prácticas habituales.

Dado las estrategias y modalidades previstas para el desarrollo de las actividades para cada una de ellas, de esa lista de contenidos, se elegirá en modo coordinado el o los temas objeto de las tareas académicas a realizar en la oportunidad de que se trate.

\subsection{Cronograma}

Las asignaturas de FADU-UNL involucradas en esta propuesta tienen distintos cronogramas y duraciones de cursado; una es cuatrimestral, la otra anual. El cronograma que se propone para este espacio curricular ampliado tratará de organizar las actividades de modo de aprovechar los recursos disponibles en ambas materias locales y a la vez ofrecer una mayor flexibilidad y posibilidad de adaptación por parte de asignaturas de universidades extranjeras en pos de establecer un cronograma común de tareas.

\section{$3 \quad$ Antecedentes de la propuesta.}

Entre los antecedentes más importantes, se citan las actividades de relacionamiento que tiene la FADU-UNL en el ámbito regional sudamericano. De ello, se cuenta inicialmente para la tarea organizativa global de una nómina de Facultades de arquitectura del Mercosur, integrantes de la red ARQUISUR; de las integrantes de la red AUGM; y otras redes.

Además se dispone como antecedentes directos en las asignaturas involucradas en esta propuesta, de una lista de Universidades de la región Latinoamericana y otras de Europa, de las cuales dependen Facultades o Escuelas de Arquitectura y de otras organizaciones, con las que -mediante diferentes programas y convenios-, ya se han desarrollado actividades académicas conjuntas relacionadas con la práctica profesional de alumnos de arquitectura en las materias Taller de Práctica Profesional y Organización de Obras de la FADU-UNL; las mismas, a título ilustrativo, se enumeran a continuación:

Universidad Autónoma del Estado de México

Universidad Federal Minas Gerais - Brasil

Universidad Estadual de Campiñas - Brasil

Universidad Autónoma de Chiapas - México

Universidad Autónoma de Sinaloa - México

Universidad Autónoma de San Luis de Potosí -México

Universidad Michoacana San Nicolás de Hidalgo - México

Universidad Mayor de San Simón - Cochabamba - Bolivia

Universidad Privada de Santa Cruz - Bolivia

Universidad César Vallejo - Perú

Universidad de La Salle - Colombia

Universitat da Coruña - España

Universidad de Valladolid - España

Universidad de Sevilla - España

Instituto Universitario de Lisboa - Portugal

Estudios de Arquitectura Particulares:

Estudio Arquitectura "UDEB ARQUITECTOS"- Arq. Felipe Uribe - Colombia

Ergo Espacio SA - Arq. Moisés E. Bernal Ponce- México

De todas estas Instituciones, se cuenta con las personas que por su rol docente, de gestión, o profesional, puedan resultar referentes clave para llevar adelante la propuesta presentada. 


\subsection{Identificación de las instituciones extranjeras y personas vinculadas a las mismas}

Como se ha mencionado, la propuesta está dirigida al conjunto de Universidades latinoamericanas que impartan estudios en la carrera de arquitectura, entre las cuales se identificará un grupo que pueda representar una síntesis a nivel de cada país y región de la diversidad de la temática que se quiere abordar, que según se plantea, será necesario y procedente llevar a cabo etapas y metas para estas vinculaciones.

La expectativa final es poder contar con la integración y la participación de los 19 países que conforman esta área continental latinoamericana; no obstante se prevé alcanzar en lo inmediato una primera etapa de integración.

\section{Conclusiones e impacto esperado.}

La implementación de la propuesta se espera tenga resultados e impactos muy beneficiosos pues, a partir de la internacionalización del currículo, se podrá acceder a la posibilidad de que cualquier alumno que participe de la misma pueda conocer y abordar esta temática disciplinar con la diversidad de visiones y particularidades que cada escenario le requiera. Escenarios y contextos, que son externos a su localización como estudiante, pero que en hipótesis puedan resultar probables lugares de su futuro desempeño profesional. A partir de la adquisición de conocimientos y habilidades lograrán aptitudes con perspectivas y competencias internacionales e interculturales que le faciliten el acceso al mundo del trabajo como arquitectos.

La definición de un conjunto de prácticas profesionales en base a un protocolo común, podrá significar un avance en sentido de allanar el camino del trabajo del arquitecto que hoy presenta cierta dispersión por la multiplicidad de situaciones disciplinares, a la vez que se advierte la integración del mercado laboral a un mundo globalizado.

Entre otros, pueden enunciarse como resultados esperados de esta propuesta:

- Fomentar las actividades con participación e interacción de estudiantes y docentes de la UNL y de otros países en el contexto de las actividades de la práctica profesional del arquitecto. - Promover la movilidad de docentes hacia los escenarios de la actividad curricular, relacionada con la temática propuesta, de Instituciones Académicas internacionales mediante participaciones individuales o colectivas que recuperen miradas desde otras perspectivas culturales.

- Que el alumno/docente pueda abordar los niveles de complejidad y profundidad propias de la práctica profesional en otros escenarios productivos (de la Región y Latinoamérica).

- Que se reconozcan los modos de aplicación y desempeños, en otros ámbitos, de los conocimientos adquiridos en el transcurso de la carrera a niveles de síntesis final.

- Que se reconozcan, verifiquen, identifiquen y en la medida de lo posible experimenten, en los escenarios propuestos, la integración e incorporación de conocimientos temáticos específicos aplicados al ejercicio profesional.

- Que se logre la observación y/o participación en el proceso de Proyecto-Gestión-Construcción de una Obra en otros escenarios; propendiendo a la vinculación y desempeños de roles profesionales en organizaciones socio productivas, entes y organismos gubernamentales, ONG y otros del medio laboral relacionado a la arquitectura. 